\title{
Surgical outcome of elective total arch replacement with coronary artery bypass grafting
}

\author{
Ken-ichi Imasaka ${ }^{1,2}$ (D) $\cdot$ Yukihiro Tomita $^{1} \cdot$ Shigeki Morita $^{1} \cdot$ Akira Shiose $^{3}$ \\ Received: 21 April 2020 /Revised: 2 July 2020 / Accepted: 7 July 2020 /Published online: 11 August 2020 \\ (C) Indian Association of Cardiovascular-Thoracic Surgeons 2020
}

\begin{abstract}
Purpose We aimed to compare the surgical outcome between total arch replacement with coronary bypass surgery and that without.

Methods Between 2008 and 2016, 157 consecutive patients underwent total arch replacement with antegrade cerebral perfusion and moderate hypothermic circulatory arrest using the proximal first approach. They were divided into two groups: total arch replacement with coronary bypass surgery (group 1, $n=38$ ) and that without (group 2, $n=119$ ).

Results Of the 38 patients in group 1, 37 (97\%) were asymptomatic. The left internal thoracic artery and saphenous vein were used in one $(2.6 \%)$ and $38(100 \%)$ patients, respectively. The mean number of coronary anastomoses was $1.5 \pm 1.0$. In-hospital mortality rate was $3.8 \%$. Cardiopulmonary bypass time and operation time in group 1 were significantly longer than those in group 2 (336 $\pm 52 \mathrm{~min}$ vs. $276 \pm 38 \mathrm{~min}, P<0.0001$ and $702 \pm 122 \mathrm{~min}$ vs. $619 \pm 94 \mathrm{~min}, P<0.0001$, respectively). No differences in in-hospital mortality and perioperative myocardial infarction were found between the groups $(5.3 \%$ vs. $3.4 \%, P=0.633$ and $0 \%$ vs. $1.7 \%, P=1.000$, respectively). In the multivariate analysis, age (odds ratio, $1.208 ; 95 \%$ confidence interval, $1.041-$ $1.497 ; P=0.008$ ) and cardiopulmonary bypass time (odds ratio, $1.019 ; 95 \%$ confidence interval, $1.001-1.041 ; P=0.041)$ were significant determinants of in-hospital mortality.

Conclusions Although prolonged cardiopulmonary bypass time was a significant determinant of in-hospital mortality, total arch replacement with coronary bypass surgery could be safely performed with favorable outcomes.
\end{abstract}

Keywords Total arch replacement $\cdot$ CABG $\cdot$ Proximal first approach $\cdot$ In-hospital mortality $\cdot$ Morbidity

\section{Introduction}

Currently, the overall hospital mortality after total arch replacement (TAR) has been declining even among elderly patients because of the improvement in surgical techniques, postoperative intensive care, and sealing grafts used in aortic

Ken-ichi Imasaka

kimasaka48@gmail.com

1 Department of Cardiovascular Surgery, Clinical Research Institute, National Hospital Organization Kyushu Medical Center,

Fukuoka, Japan

2 Department of Cardiovascular Surgery, Shimonoseki City Hospital, 1-13-1 Koyocho, Shimonoseki 750-8520, Japan

3 Department of Cardiovascular Surgery, Faculty of Medicine, Kyushu University Graduate School of Medicine, Fukuoka, Japan arch surgery [1]. However, some subgroups may be at an increased surgical risk because of preoperative comorbidity, particularly patients with significant coronary artery disease (CAD).

Generally, the concomitant coronary artery bypass grafting $(\mathrm{CABG})$ in the TAR has been considered a risk factor for adverse outcome because of prolonged myocardial ischemia and cardiopulmonary bypass (CPB) time [2]. On the other hand, some studies have reported that no significant difference in mortality and morbidity between TAR with CABG and that without $[3,4]$. Nevertheless, as the reports that focused on the effect of concomitant $\mathrm{CABG}$ are few, whether concomitant $\mathrm{CABG}$ is a risk factor for an adverse TAR outcome remains unclear. The purpose of this study was to review the clinical characteristics of patients undergoing elective TAR with or without $\mathrm{CABG}$, and to analyze the influence of concomitant $\mathrm{CABG}$ on surgical outcome. 


\section{Materials and methods}

\section{Study population}

This single-center retrospective study was approved by our institutional review board, and informed consent for surgery was obtained from all patients. Between October 2008 and December 2016, 168 consecutive patients underwent TAR with brain protection. From this cohort, we reviewed 157 patients (mean age $70.9 \pm 12.0$ years) who had elective TAR via median sternotomy alone or median sternotomy concomitant with left thoracotomy. Patients who underwent emergent surgery (acute aortic dissection or aortic aneurysm rupture) and TAR with other valve (aortic and/or mitral valve) surgery were excluded from this study. Conversely, patients who underwent TAR with the frozen elephant trunk technique or TAR with aortic root replacement (Bentall procedure) were included in this study. Preoperative invasive coronary angiography or multidetector-row computed tomography (CT) was performed in all patients. On the other hand, ischemic tests (scintigraphy, magnetic resonance imaging, or dobutamine stress echocardiography) were not routinely performed before surgery. In patients with significant coronary artery stenosis $(>75 \%$ in major branches or $>50 \%$ in the left main trunk), CABG was considered even in those who were asymptomatic.

We divided the 157 patients into two groups according to CABG status: 38 (24.2\%) underwent TAR with CABG (group 1) and 119 (75.8\%) underwent TAR without CABG (group 2). We evaluated the early surgical outcomes of the two groups.

\section{Surgical procedures (Fig. 1)}

All patients underwent elective TAR, which was performed by a single surgeon (Y.T.) with a significant experience in cardiovascular surgery.

The arterial perfusion sites were bilateral axillary arteries and the unilateral femoral artery in 148 patients $(94.3 \%)$, the right axillary artery and unilateral femoral artery in eight $(5.1 \%)$, and the left axillary artery and unilateral femoral artery in one $(0.6 \%)$. The axillary or femoral artery was used for arterial inflow, and an $8-\mathrm{mm}$ Hemashield Gold vascular graft (Maedox Medicals, Inc., Oakland, NJ, USA) was interposed to perform systemic perfusion from CPB. Moreover, we used multiple arterial inflow sites to reduce the likelihood of perioperative stroke due to embolic materials by decreasing the turbulent flow during CPB $[5,6]$.

In all patients who underwent TAR, the proximal first approach was employed to reduce myocardial ischemia during surgery. Selective antegrade cerebral perfusion (SACP) was performed for adjunctive brain protection. For a single-stage extended aortic arch repair, the L-incision approach [7] or combined median sternotomy and left posterior thoracotomy were applied for TAR.

Details of arch replacement with hypothermic circulatory arrest (HCA) and SACP have been published previously [8]. After CPB was established with bicaval drainage, left ventricular venting and systemic cooling were initiated (Fig. 1a). The proximal anastomosis with a four-branched arch graft was performed during cardiac arrest using antegrade and retrograde cardioplegia after cross-clamping of the ascending aorta. When aortic root surgery or CABG was needed, we first performed the procedures during systemic cooling after cross-clamping of the ascending aorta. Immediately after the proximal anastomosis of the prosthetic graft, the heart was reperfused from one branch of the prosthetic graft. When the rectal temperature was approximately $25-28{ }^{\circ} \mathrm{C}$, circulatory arrest of the lower body and SACP were performed (Fig. 1b). Open distal anastomosis using the elephant trunk technique was performed during moderate HCA and SACP, which was followed by systemic reperfusion through the femoral artery (Fig. 1c). In the cases of TAR with the frozen elephant trunk procedure, the J Graft Open Stent Graft or J Graft FROZENIX (Japan Lifeline, Tokyo, Japan) was implanted into the descending aorta. In most instances, cerebral perfusion, which was maintained at a perfusion rate of $10-20 \mathrm{~mL} / \mathrm{kg} / \mathrm{min}$ and a mean perfusion pressure at $40-70 \mathrm{mmHg}$, was achieved by cannulation of the left common carotid artery and inflow via synthetic grafts of the bilateral axillary arteries. In patients without axillary artery inflow, cerebral perfusion was achieved by selective cannulation of the brachiocephalic, left common carotid, and left subclavian arteries. Moreover, during coronary and systemic reperfusion, anastomosis between the proximal and distal grafts was performed. Thereafter, arch vessel's reconstruction was performed during systemic rewarming (Fig. 1d). After the repair was completed, the patient was warmed to $36{ }^{\circ} \mathrm{C}$ (rectal temperature) and weaned from CPB. Cardiac de-airing was carefully performed with transesophageal echocardiography before CPB termination.

\section{Graft arrangement in CABG}

Distal anastomoses of the saphenous vein (SV) graft or in situ graft using left internal thoracic artery (LITA) were performed during systemic cooling after cross-clamping of the ascending aorta. The SV was preferentially used for myocardial revascularization so that coronary reperfusion can be started immediately after completion of proximal anastomosis of the aorta, followed by proximal anastomosis of the SV graft on the prosthesis. 

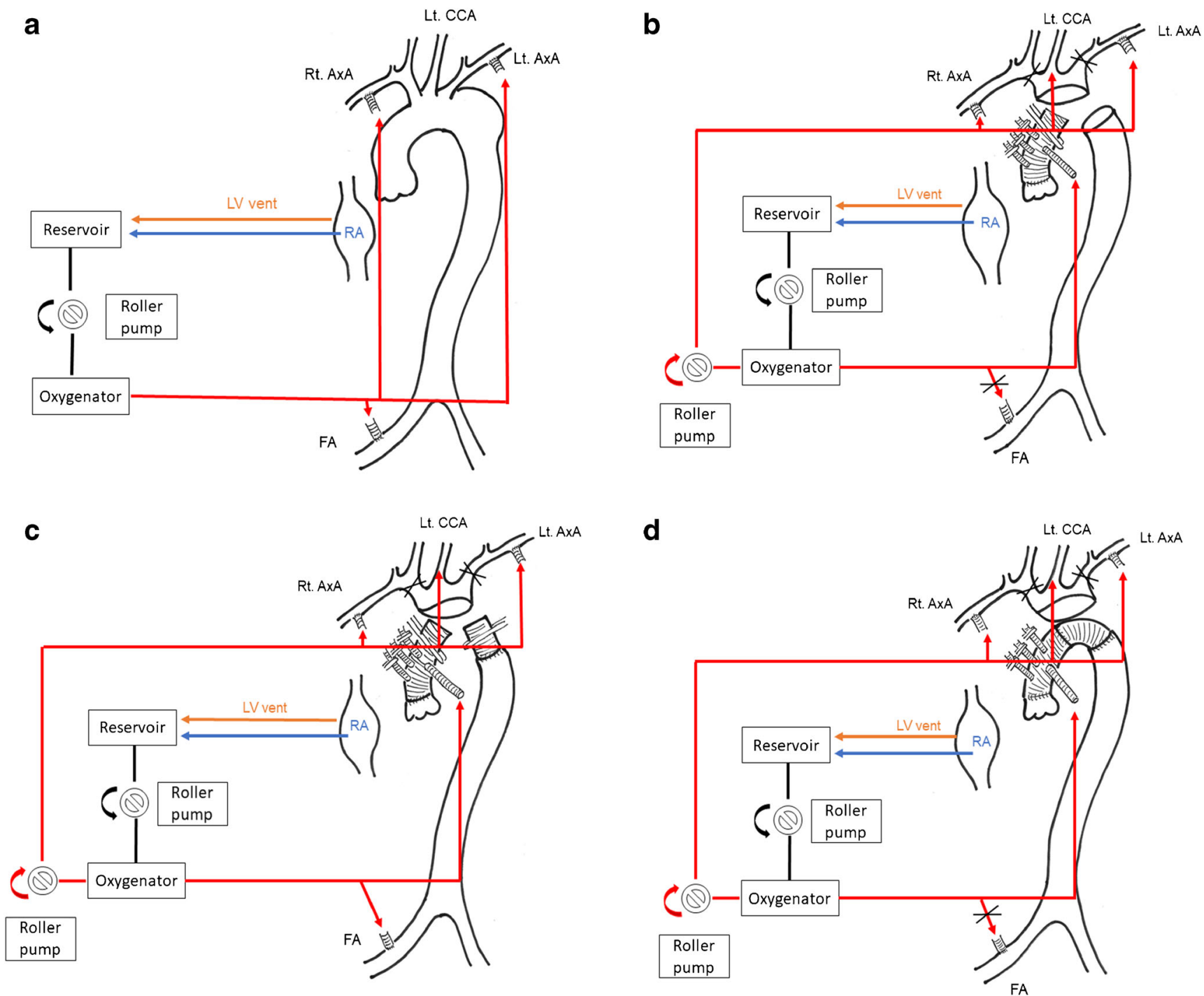

Fig. 1 Diagram of the perfusion strategy adopted during the surgery. AxA, axillary artery; CCA, common carotid artery; Lt., left; LV, left ventricle; RA, right atrium; Rt., right. Cross marks show the clamping site of the vessel or perfusion tube

\section{Definition of clinical parameters}

CAD was defined as $>50 \%$ stenosis of the left main trunk and $>75 \%$ stenosis of the 3 major branches. Carotid and/ or intracranial artery disease was defined as $>50 \%$ stenosis in the carotid or intracranial cerebral artery. Permanent neurological deficit was defined as the presence of either focal (stroke) or global (coma) neurological deficits, including cerebral stroke, that persisted after discharge from the hospital [9]. Permanent neurological deficit due to spinal cord ischemia was classified as paraplegia or paraparesis. Moreover, transient neurological deficit was described as the occurrence of postoperative confusion, agitation, delirium, and prolonged obtundation without any new structural abnormality observed on imaging [9]. Shaggy aorta was defined as a fragile and speculated atheroma measuring at least $4 \mathrm{~mm}$ based on enhanced CT or epiaortic echocardiography in the ascending aorta or the arch, excluding the aneurysm itself $[10,11]$. Perioperative myocardial infarction (PMI) was defined as a positive result for new $\mathrm{Q}$ waves in the electrocardiogram or a peak creatine kinase myocardial band (MB) level $>10 \%$ of the total creatine kinase $[3,4]$.

\section{Statistical analysis}

Data were analyzed using the statistical analysis system software JMP 12.0.1 (SAS Institute Inc., Cray, NC, USA). Categorical variables are expressed as frequencies and percentages and continuous variables as means \pm standard deviations. Statistical analyses were performed with Pearson's $\chi^{2}$ test or Fisher's test for categorical variables 
or the Mann-Whitney $U$ test for continuous variables. Pearson's $\chi^{2}$ test or Fisher's test was applied for categorical analysis using a $2 \times 2$ contingency table. We used multivariable logistic regression analysis to determine the risk factors associated with in-hospital mortality. Clinically relevant variables with $P$ value $<0.2$ on univariate analysis were entered into the multivariate analysis. The predictive accuracy of our multivariate models was assessed using the concordance index $c$. $P$ values $<0.05$ were considered statistically significant.

\section{Results}

Tables 1 and 2 show the preoperative patient characteristics and surgical data, respectively. Moreover, descriptive statistics for patients who underwent TAR with (group 1) and that without (group 2) CABG are shown in Tables 1 and 2. The number of men was significantly higher in group 1 than in group $2(87 \%$ vs. $65 \%, P=0.009)$. The proportion of patients with a shaggy aorta was significantly greater in group 1 than in group 2 (34\% vs. $18 \%, P=0.031)$. CPB time, coronary ischemic time, HCA time, SACP time, and operation time in group 1 were significantly longer than those in group 2 .

Table 3 shows the details of CAD and graft distribution in $\mathrm{CABG}$. The mean number of distal coronary anastomosis was $1.5 \pm 0.6$. The SV was preferentially used for revascularization, including the left anterior descending coronary (LAD) artery. The LITA was used in one $(3.8 \%)$ of 26 patients undergoing revascularization to the LAD artery; the patient showed angina symptoms preoperatively. Of 38 patients undergoing TAR concomitant with CABG, 37 (97\%) were asymptomatic and nine (24\%) underwent sequential bypass grafting using the SV.

The early surgical outcome is shown in Table 4. Overall 30-day mortality, in-hospital mortality, and the occurrence of PMI were $3.2 \%(n=5$; group 1/group 2: $1 / 4), 3.8 \% \quad(n=6$; $2 / 4)$, and $1.3 \%(n=2 ; 0 / 2)$, respectively. However, no significant differences in 30-day mortality, in-hospital mortality, and the occurrence of PMI between groups 1 and 2 were found $(2.6 \%$ vs. $3.4 \%, P=1.000 ; 5.3 \%$ vs. $3.4 \%, P=0.633$; $0 \%$ vs. $1.7 \%, P=1.000$, respectively). The causes of inhospital mortality were pulmonary failure in two patients (group 1/group 2: 0/2), PMI in one (0/1), non-occlusive mesenteric ischemia in one $(1 / 0)$, multiple systemic embolization in one $(0 / 1)$, and circulatory collapse due to kinking of the graft used for frozen elephant trunk in one (1/0). The etiology of PMI was inadequate preoperative coronary artery evaluation. Postoperative creatine kinase $\mathrm{MB}$ isozyme in group 1 was comparable with that in group $2(60.3 \pm 41.2 \mathrm{IU} / \mathrm{L}$ vs. $54.9 \pm 60.4 \mathrm{IU} / \mathrm{L}, P=0.148)$. Postoperative multidetectorrow CT was performed to assess graft patency in $36(95 \%)$ undergoing TAR with CABG. The overall graft patency was $100 \%$. Both groups had similar postoperative neurological complications (permanent neurological deficit: $5.4 \%$ vs. $3.4 \%, P=0.628$; paraplegia or paraparesis: $2.6 \%$ vs. $2.5 \%$, $P=1.000$; transient neurological deficit: $13.5 \%$ vs. $12.6 \%$, $P=1.000)$. Conversely, the patients in group 1 had a

Table 1 Comparison of patient characteristics between TAR with and TAR without CABG

\begin{tabular}{|c|c|c|c|c|}
\hline Variables & $\begin{array}{l}\text { Overall } \\
(n=157)\end{array}$ & $\begin{array}{l}\text { With CABG } \\
(n=38)\end{array}$ & $\begin{array}{l}\text { Without CABG } \\
(n=119)\end{array}$ & $\begin{array}{l}P \\
\text { With vs. without }\end{array}$ \\
\hline Age (SD) & $71(12)$ & $69(12)$ & $71(12)$ & 0.089 \\
\hline Male $(\%)$ & $110(70)$ & $33(87)$ & $77(65)$ & 0.009 \\
\hline Obesity (body mass index $>26)(\%)$ & $24(15)$ & $5(13)$ & $19(16)$ & 0.799 \\
\hline Diabetes mellitus (\%) & $23(15)$ & $7(18)$ & $16(13)$ & 0.450 \\
\hline Chronic renal dysfunction (serum creatinine $>2.0 \mathrm{mg} / \mathrm{dL})(\%)$ & $9(6)$ & $4(11)$ & $5(4)$ & 0.221 \\
\hline $\mathrm{COPD}\left(\mathrm{FEV}_{1.0} \%<60 \%\right.$ and/or prednisolone use $)(\%)$ & $36(23)$ & $7(18)$ & $29(24)$ & 0.448 \\
\hline Previous cerebrovascular accident (\%) & $40(25)$ & $10(26)$ & $30(25)$ & 0.892 \\
\hline CIAD & $40(25)$ & $12(32)$ & $28(24)$ & 0.322 \\
\hline Peripheral arterial disease (ankle brachial index $\leq 0.8)(\%)$ & $37(24)$ & $13(34)$ & $24(20)$ & 0.076 \\
\hline $\mathrm{EF}(\mathrm{SD}), \%$ & $68(7)$ & $66(8)$ & $68(7)$ & 0.387 \\
\hline Shaggy aorta $(\%)$ & $34(22)$ & $13(34)$ & $21(18)$ & 0.031 \\
\hline Type of aneurysm (\%) & & & & 0.556 \\
\hline Atherosclerotic (\%) & $114(73)$ & $29(76)$ & $85(71)$ & \\
\hline Chronic aortic dissection (\%) & $43(27)$ & $9(24)$ & $34(29)$ & \\
\hline
\end{tabular}

Data are presented as mean \pm standard deviation or number (percentage)

$C A B G$, coronary artery bypass grafting; $C I A D$, carotid and/or intracranial artery disease; $C O P D$, chronic obstructive pulmonary disease; $E F$, ejection fraction; $F E V_{1.0} \%$, forced expiratory volume 1-s percent; $S D$, standard deviation; $T A R$, total arch replacement 
Table 2 Comparison of surgical data between TAR with and TAR without CABG

\begin{tabular}{|c|c|c|c|c|}
\hline Variables & $\begin{array}{l}\text { Overall } \\
(n=157)\end{array}$ & $\begin{array}{l}\text { With CABG } \\
(n=38)\end{array}$ & $\begin{array}{l}\text { Without CABG } \\
(n=119)\end{array}$ & $\begin{array}{l}P \\
\text { With vs. without }\end{array}$ \\
\hline Previous cardiac surgery via median sternotomy (\%) & $6(4)$ & $2(5)$ & $4(3)$ & 0.633 \\
\hline Concomitant procedures (aortic root operation) (\%) & $5(3)$ & $1(3)$ & $4(3)$ & 1.000 \\
\hline $\begin{array}{l}\text { Extended aortic repair through L-incision or combined median } \\
\text { sternotomy and left posterior lateral thoracotomy }(\%)\end{array}$ & $16(10)$ & $5(13)$ & $11(9)$ & 0.540 \\
\hline Frozen elephant trunk technique $(\%)$ & $14(9)$ & $4(11)$ & $10(8)$ & 0.745 \\
\hline CPB time (SD), min & $290(49)$ & $336(52)$ & $276(38)$ & $<0.0001$ \\
\hline Coronary ischemic time (SD), min & $64(28)$ & $92(21)$ & $56(24)$ & $<0.0001$ \\
\hline HCA time (SD), min & $67(15)$ & $73(14)$ & $65(14)$ & 0.0009 \\
\hline SACP time (SD), min & $161(33)$ & $174(37)$ & $157(31)$ & 0.016 \\
\hline Lowest rectal temperature $(\mathrm{SD}),{ }^{\circ} \mathrm{C}$ & $26.0(4.3)$ & $25.5(1.4)$ & $26.1(4.9)$ & 0.270 \\
\hline Operation time (SD), min & $639(107)$ & $702(122)$ & $619(94)$ & $<0.0001$ \\
\hline
\end{tabular}

Data are presented as mean \pm standard deviation or number (percentage)

$C A B G$, coronary artery bypass grafting; $C P B$, cardiopulmonary bypass; $H C A$, hypothermic circulatory arrest; $S A C P$, selective antegrade cerebral perfusion; $S D$, standard deviation; $T A R$, total arch replacement

significantly more prolonged ventilation time than those in group 2 (29\% vs. 14\%, $P=0.03$ ). Moreover, group 1 tended to include higher proportions of patients with postoperative hemodialysis than group $2(16 \%$ vs. $7 \%, P=0.09)$.

Table 5 shows the univariate and multivariate analyses for in-hospital mortality. In the multivariate analysis, age (odds ratio, $1.208 ; 95 \%$ confidence interval, $1.041-1.497, P=$

Table 3 Details of coronary artery disease and CABG

\begin{tabular}{lc}
\hline Variables & Number \\
\hline Coronary artery disease $(\%)$ & $16(42)$ \\
One-vessel disease & $11(29)$ \\
Two-vessel disease & $5(13)$ \\
Three-vessel disease & $5(13)$ \\
Left main trunk & $1(3)$ \\
Others & $1.5(0.6)$ \\
Number of distal anastomosis (SD) & \\
CABG, target vessels $(n=57)$ & $26(46)$ \\
LAD & $6(10)$ \\
Dx & $12(21)$ \\
Cx & $13(23)$ \\
RCA & \\
Type of conduits & $1(3)$ \\
LITA + SVG & $37(97)$ \\
SVG & $9(24)$ \\
Sequential anastomosis &
\end{tabular}

Data are presented as mean \pm standard deviation or number (percentage) $C A B G$, coronary artery bypass grafting; $C x$, circumflex artery; $D x$, diagonal artery; $L A D$, left anterior descending artery; LITA, left internal thoracic artery; $R C A$, right coronary artery; $S D$, standard deviation; $S V G$, saphenous vein graft
0.008 ) and CPB time (odds ratio, 1.019; 95\% confidence interval, $1.001-1.041 ; P=0.041)$ were significant determinants of in-hospital mortality, whereas concomitant CABG was not a risk factor for in-hospital mortality.

\section{Discussion}

In the current study, TAR with CABG could be safely performed with favorable surgical outcomes. Moreover, the early postoperative patency rates of CABGs were excellent.

The number of patients with preoperative comorbidities, such as respiratory dysfunction, chronic kidney disease, and systemic severe atherosclerosis, undergoing TAR has increased with the aging of the society, and CABG in conjunction with TAR tends to be performed more frequently $[1,3,4]$. Ehrlich et al. described that concomitant CABG is a predictor of adverse outcome in patients undergoing elective open aortic arch surgery [2]. Nevertheless, surgical outcomes improved over the past decade because of recent advances in brain protection, surgical techniques, anesthesia, and critical care [1]. Given the discrepancies in the literature, the effect of procedures concomitant with elective TAR has not been well documented.

TAR with CABG has been considered inevitable; however, it is associated with prolonged coronary ischemia and CPB time, which may be significant risk factors for adverse outcome in open aortic arch surgery [2]. To minimize the coronary ischemic time, several techniques, such as distal coronary artery anastomosis on the perfused fibrillating heart, off-pump CABG following TAR with SACP, and coronary artery perfusion through a cardioplegic line during aortic arch repair, have been employed $[12,13]$. Yokoyama et al. reported that 
Table 4 Surgical outcomes

\begin{tabular}{|c|c|c|c|c|}
\hline Variables & Total $(n=157)$ & With CABG $(n=38)$ & Without CABG $(n=119)$ & $P$ With vs. without \\
\hline In-hospital mortality (\%) & $6(3.8)$ & $2(5.3)$ & $4(3.4)$ & 0.633 \\
\hline 30-day mortality (\%) & $5(3.2)$ & $1(2.6)$ & $4(3.4)$ & 1.000 \\
\hline Postoperative maximum CK-MB (SD), IU/L & $56.2(56.3)$ & $60.3(41.2)$ & $54.9(60.4)$ & 0.148 \\
\hline PND $(\%)$ & $6(3.9)$ & $2(5.4)$ & $4(3.4)$ & 0.628 \\
\hline Paraplegia or paraparesis & $4(2.6)$ & $1(2.6)$ & $3(2.5)$ & 1.000 \\
\hline TND $(\%)$ & $20(12.8)$ & $5(13.5)$ & $15(12.6)$ & 1.000 \\
\hline Reoperation for bleeding (\%) & $8(5.1)$ & $2(5.3)$ & $6(5.0)$ & 1.000 \\
\hline PMI $(\%)$ & $2(1.3)$ & $0(0)$ & $2(1.7)$ & 1.000 \\
\hline PCPS & $3(1.9)$ & $0(0)$ & $3(2.5)$ & 1.000 \\
\hline Required hemodialysis & $14(8.9)$ & $6(15.8)$ & $8(6.7)$ & 0.088 \\
\hline Mediastinitis & $1(0.6)$ & $1(2.6)$ & $0(0)$ & 0.242 \\
\hline Prolonged ventilation (>48 h) & $27(17.2)$ & $11(29.0)$ & $16(13.5)$ & 0.028 \\
\hline
\end{tabular}

Data are presented as mean \pm standard deviation or number (percentage)

$C A B G$, coronary artery bypass grafting; $C K-M B$, creatine kinase MB; $P C P S$, percutaneous cardiopulmonary support; $P M I$, perioperative myocardial infarction; $P N D$, permanent neurological deficit; $S D$, standard deviation; $T N D$, transient neurological deficit

off-pump CABG could minimize coronary ischemic time, thereby decreasing the risk of postoperative myocardial failure [13]. However, such an approach somewhat increases the complexity of the intervention. In our study, distal anastomosis of coronary vessels, which was followed by proximal anastomosis of the prosthetic graft, was performed during systemic

Table 5 Risk factors for in-hospital mortality in univariate and multivariate analyses

\begin{tabular}{|c|c|c|c|c|}
\hline \multirow[t]{2}{*}{ Variables } & \multicolumn{2}{|l|}{ Univariate } & \multicolumn{2}{|c|}{ Multivariate: $c$-index 0.952} \\
\hline & OR $(95 \% \mathrm{CI})$ & $P$ & OR $(95 \% \mathrm{CI})$ & $P$ \\
\hline Age, years & $1.226(1.062-1.490)$ & 0.002 & $1.208(1.041-1.497)$ & 0.008 \\
\hline Male & $1.178(0.160-6.279)$ & 0.854 & & \\
\hline Chronic renal dysfunction & $3.575(0.176-26.006)$ & 0.328 & & \\
\hline COPD & $1.509(0.233-29.396)$ & 0.700 & & \\
\hline Previous cerebrovascular accident & $3.081(0.550-17.276)$ & 0.189 & $1.022(0.117-7.369)$ & 0.983 \\
\hline CIAD & $1.487(0.200-7.934)$ & 0.662 & & \\
\hline Peripheral arterial disease & $1.657(0.223-8.864)$ & 0.580 & & \\
\hline $\mathrm{EF}$ & $1.125(0.993-1.290)$ & 0.066 & $1.104(0.974-1.286)$ & 0.128 \\
\hline Shaggy aorta & $1.859(0.250-9.975)$ & 0.501 & & \\
\hline Atherosclerotic aneurysm & $1.341(0.181-7.144)$ & 0.744 & & \\
\hline Previous cardiac surgery via median sternotomy & $5.840(0.278-46.838)$ & 0.203 & & \\
\hline Concomitant procedure (CABG) & $1.597(0.215-8.536)$ & 0.607 & & \\
\hline $\begin{array}{l}\text { Extended aortic repair through L-incision or combined } \\
\text { median sternotomy and left posterior lateral thoracotomy }\end{array}$ & $1.813(0.092-12.273)$ & 0.620 & & \\
\hline Frozen elephant trunk technique & $2.123(0.107-14.548)$ & 0.538 & & \\
\hline CPB time, $\min$ & $1.013(0.998-1.027)$ & 0.085 & $1.019(1.001-1.041)$ & 0.041 \\
\hline Coronary ischemic time, $\min$ & $1.004(0.971-1.025)$ & 0.772 & & \\
\hline HCA time, $\min$ & $1.027(0.972-1.084)$ & 0.331 & & \\
\hline SACP time, $\min$ & $1.003(0.979-1.026)$ & 0.794 & & \\
\hline Lowest rectal temperature, ${ }^{\circ} \mathrm{C}$ & $0.721(0.336-1.080)$ & 0.273 & & \\
\hline Operation time, $\min$ & $1.001(0.993-1.008)$ & 0.855 & & \\
\hline
\end{tabular}

$C A B G$, coronary artery bypass grafting; $C I$, confidence interval; $C I A D$, carotid and/or intracranial artery disease; $C O P D$, chronic obstructive pulmonary disease; $C P B$, cardiopulmonary bypass; $E F$, ejection fraction; $H C A$, hypothermic circulatory arrest; $O R$, odds ratio; $S A C P$, selective antegrade cerebral perfusion 
cooling after cross-clamping of the ascending aorta. Moreover, because of the proactive use of the SV graft, coronary reperfusion could be performed from one branch of the prosthetic graft immediately after the proximal anastomosis of the bypass graft to the prosthetic graft.

The graft design in concomitant CABG is vital. The LITALAD artery grafting has been the gold standard in isolated CABG, and patients with the LITA-LAD artery grafting are associated with improved long-term survival compared with those who received SV graft only for aortic valve replacement [14]. In our study, we preferred free graft for the following reasons: (1) coronary reperfusion could be performed immediately after proximal reconstruction of the aortic arch and CABG; (2) the use of internal thoracic artery or gastroepiploic artery with a small caliber may result in hypoperfusion and vasospasm under the circumstances of excessive bleeding [12]; and (3) sequential bypass grafting using SV graft or radial artery could reduce coronary ischemic time and $\mathrm{CPB}$ time. Moreover, 37 (97\%) of 38 patients undergoing TAR with $\mathrm{CABG}$ had asymptomatic $\mathrm{CAD}$, and $\mathrm{CAD}$ in these patients was accidentally discovered during preoperative evaluation using coronary angiography. When patients with symptoms of angina have CAD, including the LAD artery, the internal thoracic artery should be used for revascularization of the LAD artery. Proximal first approach with CABG using free grafts may be useful to reduce myocardial ischemic time during the operative procedure. However, the long-term outcome of patients undergoing CABG using SV grafts in aortic arch surgery remains unclear. Hence, further studies evaluating the midterm- or long-term outcome of these patients are warranted.

Kazui et al. performed a multivariate analysis and reported that a CPB time $>300 \mathrm{~min}$ is an independent determinant of in-hospital mortality in TAR with SACP [15]. In our study, 55 $(35 \%)$ of the patients had a CPB time $>300 \mathrm{~min}$, and CPB time was a significant determinant of in-hospital mortality. Moreover, a CPB time $>300 \mathrm{~min}$ in patients undergoing TAR with CABG was observed in $27(71 \%)$ of 38 patients (group 1 vs. group 2: $71 \%$ vs. $24 \%$, respectively; $P<0.001$ ). On the other hand, in-hospital mortality in patients who underwent TAR with CABG was comparable with those who did not undergo the procedures. The numbers of patients and adverse events were small; therefore, this study might not have had enough power to detect any increase in risk caused by the addition of CABG to TAR. Longer CPB time in patients undergoing TAR with $\mathrm{CABG}$ was attributed not only to prolonged coronary ischemic time but also to longer HCA and SACP times. Because patients undergoing TAR with CABG presented with shaggy aorta more often, a greater amount of time might be required for surgery to avoid dislodging the debris in such an aorta. In addition, the incidence of postoperative complications was higher in patients undergoing TAR with CABG. Elaborate surgical strategy and greater care are needed in patients with multiple risk factors. Cardiac surgeons must determine how CPB time and coronary ischemic time can be reduced to maximize the benefits of the CABG procedure. In the present study, distal anastomosis was performed during core cooling, and coronary circulation was restarted just after proximal anastomosis of the prosthetic graft using the proximal first approach. Hence, this approach may be useful in shortening the coronary ischemic time.

A previous study on thoracic aortic disease with CAD using the Japanese national registry database reported an approximately twofold increase in operative mortality and the incidence of major complications when aortic surgery alone was performed for significant coronary stenosis [16]. The patient who died because of PMI in our study underwent preoperative multidetector-row $\mathrm{CT}$ alone. In multidetector-row $\mathrm{CT}$, severe coronary calcification is an obstacle for an accurate assessment of the coronary arterial anatomy [17]. Since we experienced this case, invasive coronary angiography has become a routine preoperative coronary artery screening method. Before aortic arch surgery, an elaborate coronary artery evaluation is necessary.

\section{Limitations}

This study has several limitations. First, this is a retrospective study from a single center, and the study is statistically limited because of the small number of patients enrolled. Especially, because of the few adverse events in this study, it remains unclear whether the proximal first approach could reduce the operative risk. Second, because all patients with CAD underwent concomitant $\mathrm{CABG}$, a comparison between patients who underwent $\mathrm{CABG}$ and those who did not undergo CABG could not be performed. Third, little is known regarding the difference in long-term survival between LITA-LAD bypass and SVG-LAD bypass in patients undergoing elective TAR concomitant with CABG. Hence, further studies to clarify the long-term outcome are needed.

\section{Conclusions}

TAR with or without CABG could be accomplished with an acceptable surgical outcome. Because patients undergoing TAR with CABG have more preoperative comorbidities, a carefully constructed surgical strategy is crucial.

\footnotetext{
Author contributions Concept/design: KI, YT

Data analysis/interpretation: KI

Drafting article: KI

Critical revision of article: YT, SM, AS

Approve of article: KI, YT, SM, AS

Statistics: KI

Data collection: KI
} 
Funding This study was not funded by any agency or institution.

\section{Compliance with ethical standards}

Conflict of interest The authors declare that they have no conflict interest.

Ethics approval This study complies with the principles of the Declaration of Helsinki and was approved by the institutional ethics committee.

Consent to participate Informed consent was obtained from all patients included in this study.

\section{References}

1. Okada K, Omura A, Kano H, et al. Recent advancement of total arch replacement. J Thorac Cardiovasc Surg. 2012;144:139-45.

2. Ehrlich MP, Ergin MA, McCullough JN, et al. Predictors of adverse outcome and transient neurological dysfunction after ascending aorta/hemiarch replacement. Ann Thorac Surg. 2000;69:1755-63.

3. Fukui T, Shimokawa T, Tabata M, Takanashi S. Outcomes of total aortic arch replacement with coronary artery bypass grafting. Interact Cardiovasc Thorac Surg. 2011;13:284-7.

4. Takashima N, Suzuki T, Asai T, et al. Outcome of total arch replacement with coronary artery bypass grafting. Eur J Cardiothorac Surg. 2015;47:990-4.

5. Muehrcke DD, Cornhill JF, Thomas JD, Cosgrove DM. Flow characteristics of aortic cannulae. J Card Surg. 1995;10:514-9.

6. Groom RC, Hill AG, Kuban B, et al. Aortic cannula velocimetry. Perfusion. 1995;10:183-8.

7. Tominaga R, Kurisu K, Ochiai Y, et al. Total aortic arch replacement through the L-incision approach. Ann Thorac Surg. 2003;75: $121-5$.

8. Imasaka K, Tayama E, Tomita Y. The impact of carotid or intracranial atherosclerosis on perioperative stroke in patients undergoing open aortic arch surgery. J Thorac Cardiovasc Surg. 2017;153: $1045-53$.
9. Ergin MA, Galla JD, Lansman SL, Quintana C, Bodian C, Griepp RB. Hypothermic circulatory arrest in operations on the thoracic aorta. Determinations of operative mortality and neurologic outcome. J Thorac Cardiovasc Surg. 1994;107:788-97.

10. Hollier LH, Kazmier FJ, Ochsner J, Brown JC, Procter CD. "Shaggy" aorta syndrome with atheromatous embolization to visceral vessels. Ann Vasc Surg. 1991;5:439-44.

11. Katz ES, Tunick PA, Rusinek H, Ribakove G, Spencer FC, Kronzon I. Protruding aortic atheromas predict stroke in elderly patients undergoing cardiopulmonary bypass: experience with intraoperative transesophageal echocardiography. J Am Coll Cardiol. 1992;20:70-7.

12. Yokoyama H. Aortic arch aneurysm complicated with coronary artery disease: still a surgical challenge? Ann Thorac Cardiovasc Surg. 2002;8:62-8.

13. Yokoyama H, Sato Y, Takase S, Takahashi K, Wakamatsu H, Sato Y. Introduction of off-pump coronary artery bypass into aortic arch aneurysm repair: a new solution for the surgical treatment of multiorgan arteriosclerosis. J Thorac Cardiovasc Surg. 2005;129: 935-6.

14. Gall S Jr, Lowe JE, Wolfe WG, Oldham HN Jr, Van Trigt PIII, Glower DD. Efficacy of the internal mammary artery in combined aortic valve replacement-coronary bypass grafting. Ann Thorac Surg. 2000;69:524-30.

15. Kazui T, Washiyama N, Muhammad BA, et al. Total arch replacement using aortic arch branched grafts with the aid of antegrade selective cerebral perfusion. Ann Thorac Surg. 2000;70:3-8.

16. Daimon M, Miyata H, Motomura N, et al. Outcomes of thoracic aortic surgery in patients with coronary artery disease. - based on the Japan Adult Cardiovascular Surgery Database. Circ J. 2019;83: 978-84.

17. Song YB, Arbab-Zadeh A, Matheson MB, et al. Contemporary descrepancies of stenosis assessment by computed tomography and invasive coronary angiography. Circ Cardiovasc Imaging. 2019;12:e07720. https://doi.org/10.1161/CIRCIMAGING.118. 007720 .

Publisher's note Springer Nature remains neutral with regard to jurisdictional claims in published maps and institutional affiliations. 